\title{
Racionalidade tecnológica e formação humana em perspectiva: integração das TDIC na educação e o empoderamento Freiriano como possibilidade
}

\author{
Lucas Marfim (SEE-SP; UNIFESP) \\ Lucila Pesce (UNIFESP)
}

\section{Resumo}

O presente artigo situa-se como um estudo teórico-conceitual, que discute como o desenvolvimento e o espraiamento da tecnologia, sob o modo de produção capitalista e condicionados pela racionalidade tecnológica, são parte integrante de um modelo global de organização do poder, que procura conduzir os propósitos de formação humana e afetar decisivamente as políticas públicas educacionais. O texto também evidencia e problematiza as contradições afeitas às transformações socioculturais ocasionadas pela emersão das tecnologias digitais de informação e comunicação (TDIC), com vistas a discutir os limites e as possibilidades de sua integração às práticas pedagógicas. Considerando a indissociação entre as atuais práticas ciberculturais, saberes e cidadania, faz emergir a possibilidade de que essa integração seja pautada no empoderamento dos sujeitos (na acepção freireana do termo).

Palavras-chave: Racionalidade Tecnológica; Formação Humana; Tecnologias Digitais de Informação e Comunicação; Empoderamento Freireano.

\section{Racionalidad tecnológica y formación humana en perspectiva: integración de las tdic en la educación y el empoderamiento freiriano como posibilidad}

\section{Resumen}

El presente artículo se sitúa como un estudio teórico-conceptual, que discute cómo el desarrollo y la propagación de la tecnología, bajo el modo 
de producción capitalista y condicionados por la racionalidad tecnológica, son parte integrante de un modelo global de organización del poder, que conducen los propósitos de formación humana y afectan decisivamente las políticas públicas educativas. El texto también evidencia y problematiza las contradicciones afectas a las transformaciones socioculturales ocasionadas por la emersión de las tecnologías digitales de información y comunicación (TDIC), con miras a discutir los límites y las posibilidades de su integración a las prácticas pedagógicas. Considerando la relación entre las actuales prácticas ciberculturales, saberes y ciudadanía, hace emerger la posibilidad de que esa integración sea pautada en el empoderamiento de los sujetos (en al acepción freireano).

Palabras clave: Racionalidad Tecnológica; Formación humana; Tecnologías Digitales de Información y Comunicación; Empoderamiento Freireano.

\section{Technological rationality and human training in perspective: integration of Dict in Freirian educa- tion and empowerment as a possibility}

\section{Abstract}

This article is a theoretical-conceptual study, which discusses how the development and the propagation of technology, under the capitalist mode of production and conditioned by technological rationality, are an integral part of a global model of power organization, leading the purposes of human formation and decisively affect public educational policies. The text also highlights and problematizes the contradictions related to the sociocultural transformations caused by the emergence of digital information and communication technologies (DICT), to discuss the limits and the possibilities of their integration into pedagogical practices. Considering the relationship between current cyberculture practices, knowledge and citizenship, it gives rise to the possibility that this integration is based on the empowerment of the subjects (in the Freirean sense).

Keywords: Technological Rationality; Human formation; Digital Information and Communication Technologies; Freirean Empowerment. 


\section{Introdução}

É notório que as últimas quatro ou cinco décadas são marcadas pelo desenvolvimento de uma nova etapa do capitalismo, caracterizado por uma economia com capacidade de funcionar como uma unidade, em tempo real e em escala planetária. Segundo Castells (2010), tal configuração foi enormemente apoiada e intensificada pelo surgimento das tecnologias digitais de informação e comunicação (TDIC), que veloz. Mais do que servirem à reorganização do âmbito produtivo, as TDIC passaram a integrar as múltiplas práticas sociais, para além do setor economicamente produtivo (indústria, grandes empresas, setores técnicos especializados), estando presente em todo âmbito de atividades cotidianas desenvolvidas pelos cidadãos comuns.

Tal integração tem promovido novas formas de disposição, produção, manipulação e acesso de informações, conhecimentos e artes; novas formas de agremiações e relações de interesses; novas formas de produção, compra e venda de produtos; novas formas de comportamentos, atitudes e socialização, que englobam e perpassam desde interesses econômicos até a formação e o desenvolvimento intelectual e afetivo dos sujeitos, dizendo respeito àquilo que diversos estudiosos apontam como uma forma emergente de cultura: cibercultura (LÉVY, 1999), cultura digital (SANTAELLA, 2005), entre outros.

Dessas considerações, importam-nos ressaltar que o atual contexto socioeconômico, reestruturado e imbricado à emersão das TDIC, delimita tanto peculiaridades afeitas ao quadro sociocultural, quanto novas exigências para o mundo do trabalho; delimita, assim, novos direcionamentos para o âmbito formativo institucionalizado, de modo a gerar novas diretrizes e novos parâmetros para as relações entre práticas sociais e Educação; quer dizer, trata-se de que os avanços tecnológicos na comunicação e as mudanças no sistema produtivo passam a requerer novas qualificações dos cidadãos e, assim, novas exigências para a educação institucionalizada. 
Essas premissas impõem importantes problematizações a respeito dos propósitos e sentidos que norteiam as dinâmicas do cotidiano e da formação humana, efetivadas nas instituições de ensino e aprendizagem, que precisam ser conjugadas de forma relacional: tecnologia para quê e a serviço de quem? Desenvolvimento intelectivo para quê e a serviço de quem? Queremos dizer: a busca pela compreensão e análise das atuais dinâmicas da sociabilidade e da educação, marcadas de forma fundamental pelo desenvolvimento da tecnologia, nos compele a aproximar e a estabelecer relações entre essas dinâmicas e as requisições formativas gerais que as perpassam. De forma específica, procuramos captar e apontar como essas dinâmicas margeiam limites e possibilidades de integração das TDIC às práticas pedagógicas, considerando não apenas a integração e aplicação dessas tecnologias nos processos formativos, mas a contextualização dos problemas, impasses e desafios em que as relações humanas se dão, e que são indissociáveis dos embates entre marginalidade e dignidade, entre degradação e integralidade, entre limitação e liberdade, isto é, entre os problemas sociais que atravessam o modo de produção capitalista e os valores humanos que subjazem aos potenciais e às práticas educativas margeadas pelas TDIC, envolvendo tanto a alienação e a instrumentalização do ser humano, quanto o potencial para empoderamento dos cidadãos, nos termos auferido por Freire e Shor (1986).

Tendo essas considerações em vista, procuramos discutir, no presente artigo, como a atual dinâmica societária capitalista, arraigada à racionalidade tecnológica (MARCUSE, 1999) estrutura as atuais políticas públicas educacionais para a formação humana, bem como tratar sobre os limites e as possibilidades de integração das TDIC às práticas pedagógicas, considerando a necessidade de transcender a questão da apropriação e produção cultural pelos cidadãos para além do individualismo utilitarista. 


\section{Tecnologia, racionalidade tecnológica e formação humana em perspectiva}

Ao colocarmos o questionamento "tecnologia para quê e a serviço de quem?”, partimos da consideração de que sua produção e implicações na dinâmica das atividades humanas estão ligadas ao sistema econômico, político e social vigente, requerendo uma análise crítica das intenções e interesses daqueles que tanto a idealizam quanto financiam e controlam; nesse sentido colocamo-nos em concordância com Martin- Barbero (1997), para quem "As tecnologias não são meras ferramentas transparentes; elas não se deixam usar de qualquer modo: são, em última análise, a materialização da racionalidade de uma certa cultura e de um "modelo global de organização do poder”. (1997, p. 256).

Ora, compreender que a tecnologia diz respeito à racionalidade e a formação de nossa cultura e de que esta se forma sob a vigência englobante das relações de poder vigentes, requer problematizarmos as dinâmicas político-econômicas que determinam os tantos que fazeres de manutenção da própria vida, a própria racionalidade que as subjaz e, dessa forma, o estabelecimento da teia cultural em que nos movemos.

A análise de Herbert Marcuse (1999) procura demonstrar como os termos e os valores de sociabilidade, na "era tecnológica", concorrem para uma forma contextual de reificação do ser humano. Diferenciando os termos da racionalidade entre substancial e organização e a conduta humana.

Tratando do desenrolar histórico da racionalidade, diz-nos o autor que apesar do fato de que o liberalismo emergente no século XVI e XVII propunha valores de sociabilidade pautados na autonomia do indivíduo orientado pela razão, no estímulo à liberdade de pensamento, na eliminação de restrições à sua linha de ação e no livre desenvolvimento do conhecimento - princípios que emanam ou se relacionam com a racionalidade substancial -, sua análise manifesta a constatação de que o desenrolar deste processo histórico culminou em um sistema contraditório aos valores societários fun- 
dantes que propagava. Ao fazê-lo, denuncia que, se por um lado, a crescente racionalização, instrumentalização e dominação da natureza possibilitou um prodigioso desenvolvimento técnico - ligado a uma colossal capacidade de produção material da vida -, por outro lado, a própria racionalidade deixou de ser uma força crítica, escamoteada e a serviço da manutenção de uma sociedade que, apesar de sua capacidade produtiva, é marcada por profundas desigualdades. Mais do que isso, a crescente racionalização, sob os imperativos da busca de lucro, rebaixou o próprio ser humano a instrumento de um aparato que não apenas perpetua a escassez na abundância, mas que entrava qualquer possibilidade de mudança qualitativa desta mesma sociedade.

Para Marcuse (1999), isso assim é porque a tecnologia passou a ser desenvolvida e disposta como uma espécie de "suprassumo" da razão, como aparência de constante evolução social, provocando como efeito ideológico dessas disposições a aparência de vivermos a melhor forma de sociabilidade possível, posto que profundamente "racionalizada".

Diz o autor que um dos fatores ligados ao escamoteamento da força crítica da racionalidade decorre do fato de que a própria manutenção da vida, arraigada à tecnologia, passa a requerer da maioria dos envolvidos uma prontificação ao pragmatismo, uma atitude que "preze o factual e se precavenha contra [...] interpretações quase pessoais dos fenômenos observados e suas inter-relações" (1999, p. 79). Em outras palavras, a dinâmica da produção com a maquinaria dispensa uma interpretação histórica e pessoal dos processos envolvidos, do funcionamento da máquina e de seus fins. Nesse movimento, dispensa a reflexão sobre sua origem e serventia, requerendo do trabalhador fundamentalmente aquilo que a mantenha em histórico-culturais dessa configuração, o autor argumenta que:

Sob todas as formas de produção social o ser humano tem escolhido e justificado seus motivos e objetivos a partir dos fatos que compuseram sua realidade e, assim fazendo, chegou às mais diversas filosofias. A nova 
atitude se diferencia de todo o resto pela submissão altamente racional que a caracteriza. Os fatos que dirigem o pensamento e a ação do homem não são os da natureza, que devem ser aceitos para que possam ser controlados, ou aqueles da sociedade, que devem ser modificados porque já não correspondem às necessidades e potencialidades humanas. São antes os fatos do processo da máquina, que por si só aparecem como a personificação da racionalidade e da eficiência. (MARCUSE, 1999, p. 79).

Para o autor, a organização da sociabilidade no capitalismo, tendo como eixo a tecnologia e a produção através das máquinas, consuma-se como uma sociedade racionalizada instrumentalmente e em consonância com os ditames capitalistas de ganho e acumulação de riqueza, em que toda instância do fazer e ser tornam-se sujeitas à programação adequada a fins pré-estabelecidos. Nesse movimento, fecha os espaços de espontaneidade e dissolve "todas as ações em sequência de reações semi-espontâneas a normas mecânicas prescritas" (MARCUSE, 1999, p. 79). Neste contexto, a manutenção da vida (trabalho, produção e formação educacional) passa a ser indissociável da centralidade utilitária no próprio desenvolvimento formativo dos sujeitos, já que os padrões da racionalidade tecnológica - norma prescrita, eficiente, produtivista, rentável, utilitarista - colocam como imperativo que as "distinções individuais de aptidão, percepção e conhecimento [sejam direcionadas] a diferentes graus de perícia e treinamento da estrutura comum dos desempenhos padronizados" (1999, p. 78), quer dizer, os termos da formação humana, efetivadas no âmbito institucional escolar, imbricam-se aos termos de reprodução da sociedade capitalista sob os ditames da racionalidade tecnológica: adequar-se da melhor maneira possível é, consequentemente, ser racional; tornar-se útil às dinâmicas sociais constituídas, ser eficiente, seguir as regras e os "manuais de instrução" são as melhores formas - dignas e recompensadas - de participação nessa sociedade.

Nestes termos, formação intelectiva torna-se, fundamentalmente, perseguir as profissões requeridas pelo mercado (de preferência as mais rentáveis), adaptando-se às regras, processos e os pa- 
drões pré-estabelecidos de escolarização e especialização. Tratar da manutenção da vida, nestes termos, quer dizer adaptar-se ao ritmo tecnológico, aos processos burocráticos e às requisições de produtividade, desempenho e eficiência. Seguir sempre as predefinições de percurso, o aparato racional, energia são as melhores formas de conduzir a existência e o convívio social.

Desta disposição, o autor aponta, como efeito profundamente perverso, a própria atenuação dos próprios conflitos sociais, já que o ajuste individual altamente "racional" precipita-se na perda da própria força crítica que a racionalidade substancial solicitava. Se essa atitude tinha como núcleo uma batalha contra toda espécie de coerção externa, a adaptação contemporânea requer internalização constante das "recomendações" e dos comportamentos solicitados.

Ora, os fatores destacados por Marcuse (1999) impõem um problema fulcral sobre as atuais relações estabelecidas entre tecnologia e formação: o detrimento da apropriação da universalidade cultural em benefício da formação do especialista reificado da sociedade industrial-tecnológica, em que se relega a "segundo plano" qualquer apropriação e problematização de filosofia, de crenças, de arte, de juízo de valor sobre os termos de sociabilidade, de um sentido de apropriação e produção de cultura que esteja voltado ao desenvolvimento crítico e ético sobre as relações humanas. Dito de outro modo: o problema da degradação da apropriação e produção de cultura que esteja voltado ao desenvolvimento daquilo que pode dotar aos seres humanos, para além de uma profissão e do gozo sobre o que o ganho material proporciona, de reflexão crítica quanto ao direcionamento das dinâmicas sociais.

Este modelo de sistema educativo, ao deslocar as preocupações de formação humana sobre os termos da sociabilidade, do ser cidadão, dando primazia às relações de produção, permeiam as estruturas de sistemas de gestão nas escolas, configurando técnicas influenciadas por uma lógica industrial e de competências do mercado. "As questões de política e de tomadas de decisões, os interesses setoriais, são traduzidas em termos como gerenciamento, 
eficiência, produtividade.” (RIGAL, 2000, p. 184). Uma das consequências nefastas, tanto para docentes quanto discentes, implica no cerceamento da autonomia de ambos, incorrendo, como posto por Giroux (1997), na "desvalorização do trabalho crítico e intelectual de professores e estudantes pela primazia de considerações práticas." (p. 158-159).

Os termos formais educacionais se efetivam sob a égide da racionalidade tecnológica a partir de esquemas de controle externo sobre o rendimento escolar e o trabalho docente, pautado em uma construção curricular técnica e em avaliações sobre as informações recebidas pelos alunos. Aos saberes dispostos nesse tipo de construção curricular, há também a constatação de que são dispostos fundamentando-se como objetos de consumo cultural, não de apropriação crítica. (RIGAL, idem, p. 185). Giroux (1997) aponta-o como gerador de desumanização do estudante, já que essa concepção curricular não considera o estudante como sujeito idiossincrático, situado, com necessidades específicas no tocante ao seu processo de desenvolvimento:

Neste discurso, a experiência do estudante é reduzida a seu desempenho imediato e existe como algo a ser medido, administrado, registrado e controlado. Sua particularidade, suas disjunções e sua qualidade vivida são todas diluídas numa ideologia de controle e administração. (p. 127)

Como nos diz Freire e Shor (1986), ao imperativo de controle sobre o trabalho docente, à produção de currículos e materiais pré-moldados - reduzindo o trabalho a tarefas prescritas, normatizando os passos a serem aplicados em perseguição a um objetivo dado -, à subtração da mediação docente e ao postulado de uma rotina escolar "à prova de professores", impera a supressão do autogoverno, tornando o trabalho de ensino e aprendizagem controlado e controlável, confinando-o aos ditames impostos pela racionalização educacional. 
Esses currículos mecânicos frequentemente dizem ao professor quantas páginas devem ser lidas por semana, quantas palavras um estudante deve apresentar numa redação, quantas provas devem ser ministradas e a que intervalos de tempo, quantos experimentos de laboratório e quantos anos de História devem ser dados em cada período letivo, e assim por diante. Essa pedagogia se apresenta como um modelo profissional de ensino, muito bem construído, com a aprendizagem facilmente quantificada e medida, facilmente avaliada e convenientemente fiscalizada por supervisores. (FREIRE e SHOR, 1986, p. 51).

Nestes termos, a implementação das políticas públicas educacionais, marcadas pela racionalidade tecnológica configura, para além de uma redução prática dos processos de ensino e aprendizagem, a perda dos valores e do sentido próprio das pretensões de ensino, isto é, o fim social da apropriação e produção cultural, que nem de longe se esgota no desenvolvimento de competências e habilidades para inserção no mercado de trabalho. Configura, além de um controle técnico sobre a dinâmica do ensino, um controle ideológico perverso, já que retira de campo a necessidade do exercício crítico e reflexivo, a capacidade intelectual de pensar as necessidades específicas dos contextos vivenciados, de alçar as questões de aprendizagem às relações de poder, à sua imbricação política, implicando a perda progressiva do manejo sobre o conteúdo e as finalidades desejáveis na educação.

No entanto, devemos atentar que, apesar da racionalização educacional provocar a instrumentalização dos sujeitos, tal configuração não é perfeita e tampouco implacável. Porque o Estado deve legitimar-se frente ao cidadão, porque nas políticas educacionais concorrem diversos grupos com interesses antagônicos e porque a docência como trabalho não está limitada, de forma simples, ao conhecimento de "meios para fins" - mas por sua própria dinâmica requer intervenção fluída dos envolvidos, incidindo em uma teia complexa, que engloba os aspectos dispostos em uma relação de jogo, de ressignificações, contextualizações, adaptações, saberes, e que vai além, pois se ancora em uma situação de planejamento, em um imbricar entre prescrito e realizado -, podemos 
perceber que há um espaço de relativa autonomia para os agentes. (AMIGUES, 2004).

A análise da sociabilidade disposta através de Marcuse (1999) - mesmo que de forma breve -, traz à tona importantes constatações sobre as dinâmicas no seio das relações de formação humana e poder e de como as tecnologias contribuem decisivamente neste processo. Mas, para além de descrevê-las, nos parece importante frisar a percepção de que elas são levadas a cabo, em uma sociedade dividida em classes não sem luta e intervenção dos diversos atores sociais. Queremos dizer: é necessário percebermos que as decisões políticas são de importância nuclear quanto ao destino humano e as relações humanas, não a produção da tecnologia em si; mas neste sentido, nos parece que a própria produção da tecnologia, por sua importância e consequências nas relações sociais, deve estar inclusa nas discussões e decisões afeitas à participação dos cidadãos, através do processo democrático.

\section{A presença das TDIC na educação: empodera- mento freiriano como possibilidade}

$\mathrm{Na}$ medida em que as novas tecnologias intervêm nos modos de aprendizagem, no acesso à informação, na aquisição de conhecimentos e nas formas de comunicação, introduzem elementos novos na formação e na educação das pessoas. Por isso importa não apenas situar sua relevância quanto à educação no contemporâneo, mas desvendar suas possibilidades como integrantes e estruturantes de pedagogias.

Ao tratar das dos desdobramentos das TDIC no cotidiano, Santaella (2011) coloca em evidência o constructo dos novos aspectos em lidar com as informações constituídas no ambiente da internet. Para ela, o caráter marcadamente interativo e conectivo da web, com hipertextos, hiperlinks, hipermídia, modificou as formas tradicionais de leitura e aprendizagens, constituindo o leitor imersivo; acostumado a uma pesquisa dinâmica, a traçar seus pontos de interesse, a aprender sem a inflexibilidade de um caminho pré-determinado: 
O funcionamento da máquina hipertextual coloca em ação, por meio das conexões, um contexto dinâmico de leitura comutável entre vários níveis midiáticos. Cria-se, com isso, um novo modo de ler. A leitura orientada hipermidiaticamente é uma atividade nômade de perambulação de um lado para o outro, juntando fragmentos que vão se unindo mediante uma lógica associativa e de mapas cognitivos personalizados e intransferíveis. (SANTAELLA, 2011; p. 175)

Para a autora, assim como essas novas formas de organização da informação têm produzido mudanças na maneira de aprender, também estão configurando novos arranjos cognitivos, pois a interatividade e a possibilidade de múltiplas conexões midiáticas e comunicacionais perpassam "pela mente distribuída, capaz de realizar simultaneamente um grande número de operações. Observar, absorver, entender, reconhecer, buscar, escolher, elaborar e agir ocorrem em simultaneidade." (idem, p. 182). Do mesmo modo, João Mattar (2010) elenca as formas como os nativos digitais - os que nasceram e cresceram com as novas tecnologias a disposição - lidam com as TDIC, e como elas tem resultado em mudanças substanciais na dinâmica comunicativa e em apropriação e produção cultural:

Eles se comunicam diferentemente, por meio de mensagens instantâneas, chats e celulares. Eles compartilham diferentemente, em blogs, webcams e fones com câmeras. [...] Eles criam diferentemente, em sites, mundos virtuais e mods - recursos que permitem modificações em games. Eles se coordenam diferentemente, em projetos, grupos de trabalho e $M M O R$ PGs (massive multiplayer on-line role playing games, ou jogos de representação on-line e em massa para múltiplos jogadores). Eles avaliam diferentemente, utilizando sistemas de reputação on-line para avaliar posts, pessoas e atividades. [...] Eles aprendem diferentemente, pois sabem que, no momento em quiserem aprender, existe ferramentas disponíveis para ajudá-los. (MATTAR, 2010. p. 10-11)

À medida que essas novas tecnologias estão cada vez mais entranhadas ao nosso cotidiano e umbilicalmente ligadas ao processo produtivo, se tornam requisito imprescindível à escola. É assim que ocorre, na atualidade, um “boom” de anexação e tem-se visto 
instituições privadas e políticas públicas preocupadas com a questão. Em análise a essa "corrida tecnológica", Silva (2002) expõe os objetivos desses investimentos:

Eles [empresários da educação] frequentam feiras de educação e informática à procura de soluções para situações bem concretas. Exemplos: 1) melhorar a performance dos processos de gestão e de aprendizado minimizando custos e gerando lucros; 2) preparar as novas gerações para exigências atuais e futuras do mercado de trabalho onde o principal valor é a capacidade de aprender, de comunicar e de criar utilizando tecnologias digitais; 3) implementar o "ensino a distancia" como extensão da aula presencial e como mais uma opção de negócios; e 4) capacitar professores e funcionários de modo a otimizar os trabalhos de administração e aprendizagem. (SILVA, 2002, p. 22)

Evidente que a tecnologia facilitou imensamente as dinâmicas da esfera burocrática e possibilitou a abertura de novos mercados ligados à educação, mas importa saber como sua inserção no âmbito tem sido animada. É assim que, amparado na perspectiva de novas formas de sociabilidade, cultura e produção, voltamos ao questionamento: tecnologias e desenvolvimento intelectivo para quê e a serviço de quem?

Silva (2002) também expõe que, apesar da preocupação das instituições com a inserção das TDIC no cotidiano escolar, o que se tem constatado é que nas escolas que se divulgam como "interativas", que propõem a inclusão e a preparação para o "mundo digital" encontra-se muito mais modismo, argumento de venda, ideologia publicitária, dominação técnica das TDIC, etc., do que rompimento com as práticas de ensino e aprendizagem que corroboram para a formação do ser humano como instrumentalidade. (p. 22). Quer dizer, as constatações das transformações postas por Santaella (2011), Mattar (2010) e Silva (2002) não impede que a integração das TDIC às práticas educacionais seja pautada por um paradigma utilitário, instrumental.

Em sentido oposto a essa situação e reconhecendo essa disposição como enraizada e reforçada dentro das estruturas da so- 
ciedade, Paulo Freire e Ira Shor (1986) propõem outro sentido de formação, alicerçada em uma leitura de mundo que, se por um lado, percebe a desumanização como fato histórico, por outro percebe que a vocação humana é ser mais. Neste sentido, a concepção do que seja educação é envolvida pela preocupação de que a construção e aplicação do conhecimento estejam a serviço de valores e ações caras à construção de um mundo melhor, que tenha como eixo fundamental o que os autores tratam como pedagogia situada voltada ao empoderamento.

De acordo com os autores, as relações de ensino e aprendizagem vivenciados na sociedade capitalista são marcadas por relações fundamentalmente narradoras, dissertadoras, com predomínio da exposição, por parte dos professores, de conteúdos tidos como "acabados" e que pouco se remetem aos valores ou às dimensões concretas da realidade contextual dos discentes. Na medida em que as relações estabelecidas pressupõe apenas um dos atores como sujeito - tomando o discente como objeto passivo e receptivo do conhecimento - impera uma situação que coisifica e desumaniza o ser humano (FREIRE e SHOR, 1986). Este movimento, convergente com as implicações sociais da racionalidade tecnológica (MARCUSE, 1999), acaba por esvaziar o que seja conhecimento e formação, contribuindo para a petrificação das dinâmicas socioculturais e, assim, para a alienação humana.

Em profícuo diálogo sobre alternativas a este processo de aprendizagem, os autores nos dizem que é na intersecção dos assuntos acadêmicos dentro e a partir do contexto social dos educandos, dos temas críticos da cultura estudantil, colocando os objetos sociais como desafio aos dados e vivência concreta de nossas vidas, que podemos criar a oportunidade de superar o já dado, procurando transcendê-lo.

Isto ganha uma motivação intrínseca de assuntos de importância-chave para os alunos, ao mesmo tempo em que lhes dá um momento de distanciamento em relação a sua experiência prévia sobre a qual não haviam refletido. Desse modo, a pedagogia situada nos temas da cultura estudantil 
não endossa o já dado, mas, antes, procura transcendê-la. [...] Distanciamo-nos do já dado quando o abstraímos de seu contexto habitual e o estudamos de modo crítico não habitual, até que a percepção que temos dele seja contestada. (FREIRE e SHOR, 1986, p. 68)

Querem eles dizer que a integração de nossas vivências cotidianas, aliadas à apropriação do conhecimento, mais do que estarem a serviço do desenvolvimento pessoal e utilitário, possibilite a promoção do senso crítico sobre as dinâmicas sociais.

Nesse sentido, Freire e Shor (1986) trazem à tona a relação entre poder e apropriação cultural, problematizando a forma como o senso crítico pode nos capacitar à intervenção sobre nossa realidade; isto é, "a educação libertadora deve ser compreendida como um momento, um processo, ou uma prática onde estimulamos as pessoas a se mobilizar ou a se organizar para adquirir poder.” (p. 46).

Considerando essas implicações, Pesce (2014) chama atenção para a distinção entre as possibilidades de integração das TDIC nas dinâmicas pedagógicas, que podem ser tensionados entre diferentes perspectivas: se coadunado com a instrumentalização, no domínio técnico das TDIC para uso instrumental - a que a autora denomina como fluência tecnológica, diretamente relacionada à educação bancária e à racionalidade tecnológica -, ou se ligado à dimensão ontológica humana, problematizando as relações de ensino e aprendizagem nos contextos concretos das necessidades dos docentes e discentes, relacionadas ao seu desenvolvimento crítico e reflexivo como cidadãos. O segundo termo elencado (dizendo respeito ao uso contextualizado e crítico das TDIC) articula-se, para a autora, às mesmas relações entre apropriação e produção cultural e poder, articulados à discussão sobre o termo empoderamento auferido por Freire e Shor (1986).

Ao discutirem a questão do empoderamento (empowerment), os autores destoam o termo de sua conotação usual, ligada ao liberalismo - que supervaloriza o protagonismo individualista e o esforço para que o sujeito atue e se desenvolva como o self-made man $^{1}$, como 
sujeito orientado para o sucesso (como ensina Marcuse, 1999). Para Freire e Shor (1986), o empoderamento deve estar relacionado com ações, por meio das quais uma dada classe social consiga realizar, com autonomia, as mudanças que o levem ao seu fortalecimento, com vistas à promoção de transformações qualitativas das dinâmicas sociais. Asseverando que o distanciamento crítico provoca liberdade e é um passo fundamental para o empoderamento, nos dizem que não basta que esse poder, adquirido pelo senso crítico da realidade, pelo saber, se encerre no âmbito da atividade individual, mas deve estar a serviço da superação das tensões que perpassam a divisão social de classes e a cidadania, as desigualdades envoltas na dominação do ser humano sobre o ser humano e a busca da superação de nossa atual condição. Nesse sentido, de forma relacional às questões levantadas no início, podemos também dispor que há necessidade de explicitar resposta ao seguinte questionamento: A favor de quem ou contra quem esse poder está sendo posto em uso?

A questão do empowerment da classe social envolve a questão de como a classe trabalhadora, através de suas próprias experiências, sua própria construção de cultura, se empenha na obtenção de poder político. Isto faz do empowerment muito mais do que um invento individual ou psicológico. Indica um processo político das classes dominadas que buscam a própria liberdade da dominação, um longo processo histórico de que a educação é uma frente de luta." (FREIRE e SHOR, 1986, p. 72)

Dispomos assim que a relação entre Empoderamento, Educação e TDIC, mais do que ter a preocupação em integrar as TDIC às práticas pedagógicas, deve estar atenta à promoção de práticas sociais e culturais que contribuam para a construção do empoderamento da classe trabalhadora, imbricando os processos de ensino e aprendizagem aos contextos de trabalho, às vivências culturais dos sujeitos, valorizando e redimensionando criticamente essas vivências afeitas às dimensões envoltas às lutas políticas e cidadãs. Sina-

Expressão estadunidense que indica o homem que se eleva por seus próprios méritos. Que abre seu caminho na vida por si mesmo. 
lizamos também que a promoção de situações de aprendizagem, amparadas ou vivenciadas através de e nos ambientes formativos proporcionados pelas TDIC, deve considerar os fatores potencializados pela cultura digital e atuar em consonância com a promoção do senso crítico, atento às possibilidades de que a produção do conhecimento seja construída de forma a possibilitar aos docentes e discentes criatividades, inovações, inventividades e a ressignificação da apropriação e produção cultural humana.

\section{Considerações finais}

Procuramos discutir, ao longo deste artigo, sobre as contradições afeitas às relações entre produção da tecnologia na sociedade capitalista, a racionalidade que a subjaz e suas implicações na teia da sociabilidade e das políticas para a Educação, propondo a problematização de questões fundamentais para pensarmos sobre formação humana: tecnologia, apropriação cultural e poder para quê? A serviço de quem?

Neste sentido, dissemos que a integração das TDIC aos processos de ensino e aprendizagem pode tanto estar ancorada em práticas socioculturais e na possibilidade de empoderamento dos sujeitos, nos termos auferidos por Freire e Shor (1986) - dispostas à contramão das requisições do status quo -, quanto margear a possibilidade de "continuísmo" do automatismo e da alienação, a depender dos sentidos que se estabelecem aos "porquês" e aos "comos" de sua integração; às formas com que se estruturam os processos de ensino e aprendizagem - tendo como preocupação a formação dos sujeitos para além da instrumentalização voltada à produtividade, ao desempenho e a eficiência.

Neste sentido, defendemos que, mais do que perceber que a integração das TDIC às práticas educativas tem importância fundamental no contemporâneo, que as formas de sua inserção estejam atentas aos condicionantes e às lutas travadas entre a reificação e a humanização, entre a autonomia e o automatismo, entre a vocação para ser mais e ser desumanizado. 


\section{Referências}

AMIGUES, R. Trabalho do professor e trabalho de ensino. In: MACHADO, A. R. (org.) O ensino como trabalho: uma abordagem discursiva. Londrina: Eduel. 2004.

CASTELLS, M. A Sociedade em rede. Trad. Roneide Venâncio Majer; Atualização para $\sigma^{\mathrm{a}}$ ed.: Jussara Simões. São Paulo: Paz e Terra. 2010.

LÉVY, P. Cibercultura. Trad. Irineu da Costa. São Paulo: Editora 34, 1999.

FREIRE, P. e SHOR, I. Medo e ousadia: O cotidiano do professor. Trad. Adriana Lopez. $1^{a}$ ed. Rio de Janeiro: Paz e Terra. 1986. (Educação e Comunicação)

GIROUX, H. A. Os professores como intelectuais: rumo a uma pedagogia crítica da aprendizagem. Trad. Daniel Bueno. 1ª ed. Porto Alegre: Artes Médicas. 1997.

MARCUSE, H. Algumas Implicações Sociais da Tecnologia. In: Tecnologia, guerra e fascismo: coletânea de artigos de Herbert Marcuse. Trad. Maria Cristina Vidal Borba. São Paulo. Editora UNESP. p. 74-104. 1999.

MARTIN-BARBERO, J. Dos meios às mediações: comunicação, cultura e hegemonia. Trad. Ronald Polito e Sérgio Alcides. Rio de Janeiro: Editora da UFRJ, 1997.

MATTAR, J. Games em educação: como os nativos digitais aprendem. $1^{\text {a }}$ ed. São Paulo: Pearson Prentice Hall, 2010.

PESCE, L. Políticas de formação inicial de professores, tecnologias e a construção social do tempo. EccoS, Revista Científica. v. 33, n. 01, jan.-abril. p. 157-172. 2014. Disponível em: http://www4.uninove.br/ojs/index.php/eccos/article/viewFile/3598/2721

RIGAL, L. A escola crítico-democrática: uma matéria pendente no limiar do século XXI. In: A educação no século XXI: Os desafios do futuro imediato. IMBERNÓN, F. de (org.). Tradução por Ernani Rosa. $1^{\mathrm{a}}$ ed. Porto Alegre: Artmed, 2000.

SANTAELLA, L. Potenciais e desafios da sociedade informacional. Anais do IX Congresso Mundial em Informação em Saúde e Bibliotecas: compromisso com a equidade. Conferência magistral. Salvador. 2005. Disponível em: http://www.crics.info/program/public/documents/salvadorsantaella-141327.pdf

SANTAELLA, L. Navegar no ciberespaço: o perfil cognitivo do leitor imersivo. $4^{\mathrm{a}} \mathrm{ed}$. São Paulo: Paulus, 2011. (Comunicação)

SILVA, M. Sala de aula interativa. 3a ed. Rio de Janeiro: Quartet. 2002. 


\section{LUCAS MARFIM}

CV LATTES: http://lattes.cnpq.br/8510059674218646 ORCID: https://orcid. org/0000-0002-9854-3489

e-mail: lmarfim@hotmail.com telefone: (11) 99495-0236

Endereço: Rua Carlos Nicola, 275, Jundiaí, SP, CEP: 13219-480

\section{LUCILA PESCE}

CV Lattes: http://lattes.cnpq.br/4867232275873194 ORCID: http://orcid. org/0000-0002-2562-2012

e-mail: lucilapesce@gmail.com telefone: (11)99940-1231 Endereço residencial: Rua Carlos Weber, 1319 apto. 162, Vila Leopoldina SP, SP, CEP: 05303-000 